\title{
Effect of climatic factors on forest succession in the forest- steppe zone of the Republic of Tatarstan
}

\author{
Irek Singatullin ${ }^{1, *}$, Zulfiya Khakimova $^{1}$, Vasily Chernov $^{2}$, and Rustam Davletshin ${ }^{1}$ \\ ${ }^{1}$ Kazan Agrarian University, 420015 Kazan, Russia \\ ${ }^{2}$ Ministry of Forestry of the Republic of Tatarstan, 420124 Kazan, Russia
}

\begin{abstract}
The paper analyzes the effect of climatic factors on forest succession in the forest-steppe zone of the Republic of Tatarstan. A reliable relationship was revealed between a decrease of the oak forested area and extremely low frosts in 1939-1940, 1941-1942 and 1978-1979, and a decrease in the area of birch after the 2010 drought. Birch and oak are replaced by maple, linden and aspen. Insignificant amount of young trees and the predominance of ripe and overripe plantations of oak and birch will lead to the continuation of forest succession in the forest-steppe zone. Impossibility of reverse succession at this stage by natural rehabilitation is associated with the biological characteristics of these species. Oak and birch forest rehabilitation is only possible with measures to promote natural or artificial regeneration with due regard to the biological characteristics of tree species.
\end{abstract}

\section{Introduction}

Succession (from Latin word successio) is a successive replacement of one biogeocenosis (biocenosis, phytocenosis) in a particular area by another one [1].

The general theory of plant successions as a theory of community dynamics was proposed by G.K. Cowles [2]. The classical theory of successions was developed by the American botanist F.E. Clements [3]. The fact that successions are most pronounced in forest biogeocenoses attracted attention of the leading Russian forestry specialists and geobotanists - S.I. Korzhinsky, G.F. Morozov, V.N. Sukachev, T.A. Rabotnov and many others [4-7]. The classification of V.N. Sukachev is now mostly recognized and considers succession to be an irreversible process of dynamics and changes in forest biogeocenoses that gives it an evolutionary meaning, G.F. Morozov associated succession with human activity only.

Global climate warming affects the state and productivity of forests $[8,9]$. An increase in average annual temperature by $1.5^{\circ} \mathrm{C}$ or more has recently been observed for most areas covered by boreal forest [10]. Studies have established a relationship between changes in the area of prevailing species and temperature trends. In addition, statistically significant correlations with temperature increase are demonstrated by a number of tree species: stone birch, birch, gray alder, willow (positive correlations), and spruce, cedar, oak, poplar (negative correlations) [11, 12].

Succession occurring in the forest-steppe zone have long attracted the attention of foresters. They are primarily associated with the degradation of oak forests in European countries and Russia. The most significant causes are changes in climatic conditions, periodic droughts, and the associated drop in groundwater levels, as well as periodic mass reproduction of leaf-eating insects and the development of fungal diseases [13-15]. These led to a decrease of the oak forested area and its replacement with mixed deciduous stands without oak $[16,17]$.

\section{Materials and methods}

The source material for the analysis was data from the state registration of forest fund starting from 1938. Changes in the forest composition were observed on permanent sample plots with at least 200 trees over 20 years (1996-2017) After the drought of 2010, forest stands with more than 10 thousand drying strata were analyzed for more than 100 temporary sample plots in 20 forestries of the Republic of Tatarstan. The condition of trees was evaluated according to 6 categories, and undergrowth was calculated with regard to the size category by species.

\section{Results and discussion}

One of the abnormal weather conditions that affected the state of oak forests and species succession in forests of the Republic of Tatarstan was severe frosts in the winter of 1939-1940, 1941-1942 and 1978-1979, when temperature dropped below 45 degrees. The area of oak forests decreased by 124.4 thousand ha [18]. Part of the area (43.9 thousand ha) was replaced by linden forests, more than 20 thousand ha turned into sparse stands. The stock of forested areas decreased by $14 \%$, and ripe areas

*Corresponding author: betula2@mail.ru 
were observed to decline by $18 \%$. The stand density decreased by $18 \%$. A total area of 249.4 thousand ha of oak plantations in Bugulminsky, Kaybitsky, Kamsky, Kzyl-Yulduz, Laishevsky, Mamadyshsky, Privolzhsky and Tetyushsky forestries were severely damaged.

The state and composition of forests of the Republic of Tatarstan were greatly affected by the drought of 2010, the consequences of which are as yet underestimated and insufficiently analyzed. In 2010, the hydrothermal coefficient in the republic was only 0.4 with an average annual rate of 1.2. The average monthly air temperature exceeded the norm by $4-6{ }^{\circ} \mathrm{C}$, and July and August were the hottest months for the entire period of meteorological observations in the republic [19]. A sharp decrease in groundwater levels led to the groundwater capillary rise from the root systems, which causes the death of trees. In this case, the death of plants occurred even before their complete dehydration as a result of nutritional disorder [20]. First of all, species with a lateral root system were affected - European spruce, Siberian spruce and birch; aspen was also affected in the forest-steppe zone [21]. In terms of forest succession, the area of forests affected by drought can be compared to that affected by frosts. In both cases succession occurs over several decades.

Forest regulation data and our studies indicate a decrease in the birch forested area and an increase in the area of plantations with a predominance of maple and linden in all forestries of the forest-steppe zone after the 2010 drought (Table 1). An increased share of these species in the forest fund does not indicate their rehabilitation; an analysis of this relationship is presented below.

Table 1. Change in the area of dominant tree species in forests of the Republic of Tatarstan after the 2010 drought, ha*

\begin{tabular}{|l|c|c|c|c|c|}
\hline \multirow{2}{*}{ Forestry } & \multicolumn{5}{|c|}{ Change in the area of dominant tree species, ha* } \\
\cline { 2 - 6 } & oak & maple & birch & aspen & \multirow{2}{*}{ linden } \\
\hline Bugulminsky & 959 & 434 & -1659 & 94 & 497 \\
\hline Zainsky & -102 & 1022 & -951 & -76 & 784 \\
\hline Leninogorsky & -291 & 1256 & -978 & -9 & 427 \\
\hline Almetevsky & 663 & 1191 & -1463 & -1312 & 1330 \\
\hline Aznakaevsky & 982 & 1026 & -745 & 55 & 81 \\
\hline
\end{tabular}

*difference between forest regulation data in 2004-2005 and 2014-2017 (minus indicates a decrease in the area)

A detailed analysis of the effect of adverse climatic factors on species succession was carried out on four most typical forest stands in Bugulminsky forestry based on the forest regulation data of 1938, 2004 and 2015 and on data obtained in studies carried out in 1996-2015 on permanent sample plots (Fig. 1).

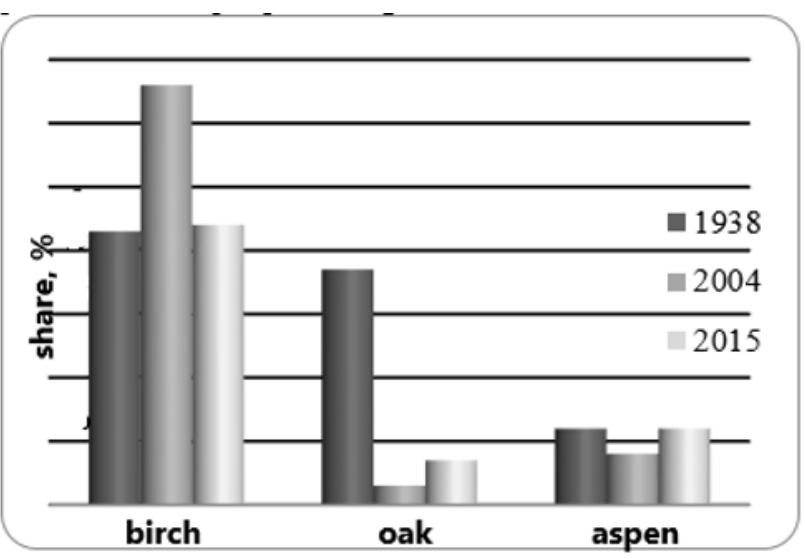

Fig. 1. Change in the share of main forest-forming species from 1938 to 2015

It was revealed that the area of oak forests decreased and succession to birch occurred after the frosts of 19391940, 1941-1942 and 1978-1979. The share of the oak forested area decreased from $35 \%$ in 1938 to $4 \%$ in 1993 , the birch forested area increased from $43 \%$ to $63 \%$, respectively, the share of aspen forests decreased slightly. After the drought of 2010, the share of birch forests decreased from $64 \%$ to the level observed in 1938 (44\%), the area of oak forests increased slightly (by $3 \%$ ), the share of aspen forests increased by 2 times. Insignificant increase in the share of oak forests does not indicate its rehabilitation, this is due to birch drying since oaks and birches are arranged in clumps in mixed oak-birch forests forming microcenoses, which leads to species succession. When one of the species disappears due to adverse weather conditions, the stand turns to birch or oak forest. By 2015, the average age of oak increased from 38 years in 1938 to 88 years old. Birch of seed and overgrown origin appeared on part of the area after cutting of dead oak, its average age in 2004 was 64 years, in 2015 it decreased to 44 years old. This is due to both birch drying after 2010 in the area of 40 ha inhabited by predominantly ripe and overripe trees and felling of ripe stands of more than 61 years old. Even small amount of aspens with high growth capacity replace birch, which is evidenced by its young age -18 years. After birch drying, undergrowth of the composition $7 \mathrm{M} 3 \mathrm{~L}$ appeared under the canopy, the average number was 4 thousand ind/ha, birch undergrowth was not observed. Three plots exhibited insignificant amount of oak undergrowth, up to 3 thousand ind/ha, but our studies indicate that most part of young trees die within 3-5 years. There were no young and middle-aged oak stands. In 2015, the share of artificial plantations of pine and spruce increased in the studied areas and amounted to $30 \%$.

The effect of the 2010 drought on succession in birch forests was also investigated in other forestries. In 
Almetyevsk forestry, the average composition of stands with completely dried birch was $8 \mathrm{~B} 2 \mathrm{O}+\mathrm{A}+\mathrm{M}$ in 2004, the average age of trees was 76 years. In 2018, the composition was replaced by $5 \mathrm{M} 2 \mathrm{O} 2 \mathrm{~A} 1 \mathrm{~B}+\mathrm{L}$, the average age of maple and linden trees was 10 years.

In Leninogorsk and Bavlinsky forestries, birch drying led to the occurrence of undergrowth of $10 \mathrm{M}$ composition in an amount of more than 5,000 ind/ha that covered $80 \%$ of the area. Birch undergrowth was not observed in the studied areas.

Similar to oak, maple was severely affected by frosts, its share in the forest fund in the studied area fell from $2.9 \%$ in 1938 to $1.3 \%$ in 1993 . After the drought of 2010, maple not only regained its position, but also increased its share in the forest fund of the forest-steppe zone of the Republic of Tatarstan. The average age of maple is 35 years, a small amount of ripening and ripe stands is associated with frosts. In the stands of oak or birch, maple occupies the second tier; the average diameter is 1.5-2 times smaller than that in the main forest-forming species. Studies established the presence of maple undergrowth with a height of not more than $0.5 \mathrm{~m}$ under the canopy of plantations. After birch drying, maple actively occupies the area. This is due to its biological characteristics to propagate well by vegetative and seed methods, bear fruit abundantly almost every year. In clearings, young trees reach $1.5 \mathrm{~m}$ in height in 5 years, at the age of 5 years its height is $4-5 \mathrm{~m}$, and its intensive growth continues to 25-30 years old [22].

A reliable correlation of the number of maple undergrowth on the distance to seed trees was established - the maximum number of trees can be observed at a distance of up to 40 meters (up to 20 thousand ind/ha), and no undergrowth was found at a distance of $100 \mathrm{~m}$. The replacement of oak and birch with linden is associated with its high growth capacity the number of shoots on a stump varies from 3 to 28 , in a year after felling it reaches a height of 1.5-2.0 meters and suppresses undergrowth of other species. After drying of oak and birch, it becomes the dominant species.

After 2010, the replacement of birch to aspen occurs when the number of aspen in the composition is three. Since aspen exhibits high root-sprinkling capacity, it occupies the entire vacant area within 1-2 years after birch drying. In Alkeevsky forestry, the stand composition before drying was 8B2A; after felling, the stand composition of $8 \mathrm{~A} 1 \mathrm{M} 1 \mathrm{~L}+\mathrm{E}$ was formed, the number of undergrowth was more than 10 thousand ind/ha. The amount of aspen undergrowth after felling can be up to 50 thousand ind/ha and form low-quality clean aspen forests, which begin to decay at the age of 40 years old. Species succession needs the control of the felling period - during summer felling, the number of aspen undergrowth is less, and it is possible to form stands mixed with linden and birch.

Oak is indigenous and most valuable species for the forest-steppe zone, and its rehabilitation is of high priority for foresters. The share of young oak trees up to 20 years old in the Republic of Tatarstan was only 4\% taking into account artificial reforestation as of 01.01.2019. Studies revealed oak undergrowth under the canopy of the maternal stand in large areas. In Nurlatsky forestry, in 2017, under the canopy of the composition 100 aged 90 years and the size of 0.5 , oak undergrowth was found in an amount of more than 3 thousand ind/ha, which belonged to the small size category $96 \%$ (up to $0.5 \mathrm{~m})$.

Self-seeding of oak under the canopy of the mother stand can be observed constantly, but a number of factors (lack of light, dynamics of air humidity, temperature) lead to its death. An age of 3 years is critical for oak self-seeding regardless of the structure, size, and age of the mother stand [4]. In mixed birch-oak stands, after birch drying, oak undergrowth of seed origin of various size categories can be found in certain areas in an amount sufficient for the formation of a stand. In Aznakaevsky forestry, in the stand composition of $8 \mathrm{~B} 2 \mathrm{O}$, oak undergrowth in an amount of about 5 thousand ind/ha, more than half of which can be referred to middle stand, can be observed under the canopy after birch drying. In Bugulminsky forestry, the dependence of the undergrowth amount and composition on the location on the slope was revealed (Fig. 2).

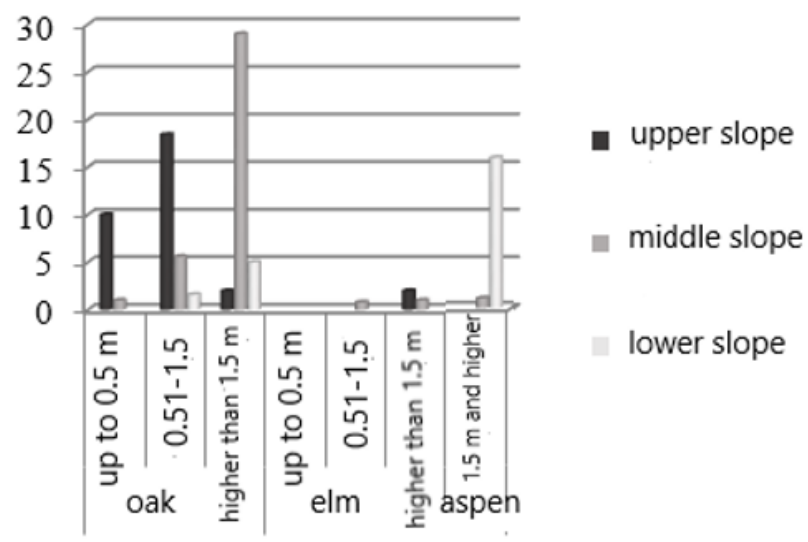

Fig. 2. Distribution of undergrowth by species and size categories depending on their location on the slope.

The best conditions for the growth of oak undergrowth are observed in the middle slope, whereas the upper slope is characterized by high solar insolation. In the lower slope, oak is usually replaced by aspen due to humid conditions.

The best conditions for the oak rehabilitation and growth can be found in the deciduous litter of linden and elm, or birch and aspen. Young oak trees with an admixture of the above species of composition 8O2L + B, A, E, aged 15 years, size of 0.7 , were examined in Menzelinsky forestry. Oak has a smaller diameter if compared to other species, and is slightly inferior in height. Our studies show the possibility of formation of high-productive oak stands of seed origin.

Artificial oak rehabilitation is often ineffective due to the fact that young trees are planted on clearings and most of them are suppressed by soft-leaved species or die from frosts.

Birch is a valuable species of the forest-steppe zone due to high demand for wood. Birch forests of the foreststeppe zone in most cases are derived from oak forests. Succession occurred mainly in the last $50 \ldots 100$ years. 
Similar to oak, the share of young trees in birch forests is less than $4 \%$. The average age of birch forests in the forest-steppe zone is about 70 years, and its maximum life span is 80 years [23]. This causes a complete decay of overripe birch forests that survived after drought; succession to plantations with a predominance of maple, linden and aspen is likely to occur in the next 20 years. Low capacity of birch to recover under conditions of the forest-steppe zone is associated with low seed germination, severe soil sodding, and adverse weather conditions for self-seeding. [24] The promotion of natural rehabilitation by the soil mineralization with a plough or bulldozer dump is crucial for birch selfseeding. In Bavlinsky forestry, undergrowth of various compositions $-10 \mathrm{M}$ in the amount of 10 thousand ind/ha on the clearing without mineralization of soil, and 9B1M in the amount of 5 thousand ind/ha on the plot with plough furrows - was observed on the adjacent plots. Birch crops are cultured in an insignificant area due to the lack of planting material that can be grown in the forest-steppe zone only in the protected ground.

\section{Conclusion}

Due to the variety of factors affecting forest succession, we were not able to identify a reliable relationship between the species composition dynamics and climate change over the last 80 years in the Republic of Tatarstan. The effect of climatic factors abnormal for a given territory on forest succession was confirmed. Thus, the frosts in 1939-1940, 1941-42, and 1978-79 reduced the area of oak forests, and drought in 2010 caused a decrease in the birch forested area. These species were replaced by maples, lindens and aspens, which is associated with their high reproductive efficacy and resistance to adverse factors at a young age. The age structure of oak and birch forests is changing - ripe and overripe stands prevail, which will further reduce their share in the forest fund. Oak and birch forest rehabilitation is a priority for foresters, which is only possible with measures to promote natural or artificial forest regeneration with regard to the biological characteristics of tree species.

\section{References}

1. Yu. Odum, Fundamentals of Ecology (Mir, Moscow, 1975)

3. F.E. Clements, Plant succession (Carnegie Inst. Wash. Publ., 1916)

4. S.I. Korzhinsky, Northern border of Chernozem region of the eastern zone of European Russia in the botanical and geographical and soil aspects in Proc. of Kazan community of natural scientists 22(6), 144-145 (1891)

5. G.F. Morozov, Forestry studies Forest Journal 1, 230245 (1908)

6. V.N. Sukachev, N.V. Dylis, Dynamics of forest biogeocenoses in Fundamentals of Forest Biogeocenology 458-486 (Nauka, Moscow, 1964)
7. T.A. Rabotnov, On types of plant successions Bull. of Moscow community of nature investigators 100(1), 85-86 (1995)

8. J. Legatt, Ed., Global Warming: Greenpeace Report (Moscow State University, 1993)

9. J.T. Houghton, Y. Ding, D.J. Griggs, et al., IPCC: Climate change 2001: Scientific basis. Contribution of working group I to the third assessment report of the Intergovernmental panel on Climate Change (Cambridge University Press, Cambridge, United Kingdom and New York, NY, USA, 2001)

10. T. F. Stocker et al., Eds, Intergovernmental Panel on Climate Change (IPCC), Climate Change 2013: The Physical Science Basis. Contribution of Working Group I to the Fifth Assessment Report of the Intergovernmental Panel on Climate Change (Cambridge, 2013)

11. V.A. Alekseev, M.V. Markov, Forest statistics and changes in forest productivity in Russia in the second half of the 20th century (St. Petersburg Forest Environmental Center, 2003)

12. V.P. Ivanov, S.I. Marchenko, I.N. Glazun, D.I. Nartov, L.M. Soboleva, Changes in the biogeocenoses of the central part of Bryansk region after the summer heat of 2010 Bulletin of Perm State Technical University 1, 25-35 (2013)

13 V.V. Osipov, Ecosystems of the Tellerman Forest (Nauka, Moscow, 2004)

14.V.V. Rubtsov, I.A. Utkina, Oak adaptation reactions to defoliation (Grif and Co., Moscow, 2008)

15. V.G. Storozhenko, V.M. Kotkova, P.A. Chebotarev, Dynamics of transformation of indigenous oak forests and wood-destroying basidiomycetes of the Tellerman forest (Voronezh region) Forest Herald 4(18), 77-85 (2014)

16. V.V. Chebotareva, P.A. Chebotarev, V.G. Storozhenko, Trends in the natural change of oak stands to mixed deciduous stands in the foreststeppe zone (through the example of stands of the Tellerman Experimental Forestry of the ILAN RAS) Ulyanovsk Biomedical J. 2, 172-179 (2017)

17. N.A. Kharchenko, N.N. Kharchenko, E.E. Melnikov, Succession processes in the oak forests of the Central forest-steppe as a result of their degradation Forest Herald 5, 192-195 (2009)

18. I.A. Yakovlev, A.S. Yakovlev, Oak forests of the Middle Volga region (history, causes of degradation and current state Retrieved from: http://oaks.forest.ru/publications/

19. State report on the state of the environment for 2010 (Kazan, 2011)

20. A.V. Veretennikov, Plant Physiology (Academic project, Moscow, 2006)

21.I.K. Singatullin, Effect of the 2010 drought on the state of forests of the Republic of Tatarstan Bulletin of Kazan Agrarian University 3, 40-45 (2018)

22. A.D. Bukshtynov, Maple (Forest Industry, Moscow, 1982) 
23. V.G. Atrokhin, Forestry and dendrology (Forest Industry, Moscow, 1982)
24. K.V. Krasnobaev, I.K. Singatullin, S.Yu. Mityashina, I.F. Lukin, On the dynamics of fruiting of a birch tree (Betulapendula Roth.) Forestry 1, 33-34 (2007) 